\title{
A pure variation of risk in first-price auctions
}

Citation for published version (APA):

Kirchkamp, O., Reiss, J. P., \& Sadrieh, A. (2006). A pure variation of risk in first-price auctions. METEOR, Maastricht University School of Business and Economics. METEOR Research Memorandum No. 058 https://doi.org/10.26481/umamet.2006058

Document status and date:

Published: 01/01/2006

DOI:

10.26481/umamet.2006058

Document Version:

Publisher's PDF, also known as Version of record

\section{Please check the document version of this publication:}

- A submitted manuscript is the version of the article upon submission and before peer-review. There can be important differences between the submitted version and the official published version of record.

People interested in the research are advised to contact the author for the final version of the publication, or visit the DOI to the publisher's website.

- The final author version and the galley proof are versions of the publication after peer review.

- The final published version features the final layout of the paper including the volume, issue and page numbers.

Link to publication

\footnotetext{
General rights rights.

- You may freely distribute the URL identifying the publication in the public portal. please follow below link for the End User Agreement:

www.umlib.nl/taverne-license

Take down policy

If you believe that this document breaches copyright please contact us at:

repository@maastrichtuniversity.nl

providing details and we will investigate your claim.
}

Copyright and moral rights for the publications made accessible in the public portal are retained by the authors and/or other copyright owners and it is a condition of accessing publications that users recognise and abide by the legal requirements associated with these

- Users may download and print one copy of any publication from the public portal for the purpose of private study or research.

- You may not further distribute the material or use it for any profit-making activity or commercial gain

If the publication is distributed under the terms of Article $25 \mathrm{fa}$ of the Dutch Copyright Act, indicated by the "Taverne" license above, 
Oliver Kirchkamp, J. Philipp Reiss, Abdolkarim Sadrieh

A pure variation of risk in first-price auctions $\mathrm{RM} / 06 / 058$

JEL code : C92, D44

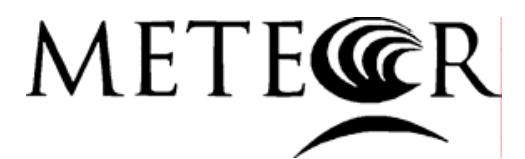

Maastricht research school of Economics of TEchnology and ORganizations

Universiteit Maastricht

Faculty of Economics and Business Administration P.O. Box 616

NL - 6200 MD Maastricht

phone : :+31 433883830

fax : $\quad++31433884873$ 



\title{
A pure variation of risk in first-price auctions*
}

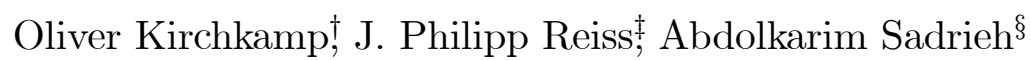

December 03, 2006

\begin{abstract}
We introduce a new method of varying the risk that bidders face in first-price private value auctions. We find that decreasing bidders' risk significantly reduces the degree of overbidding relative to the risk-neutral Bayesian-Nash equilibrium prediction. This implies that risk affects bidding behavior as generally expected in auction theory. While resolving a long-standing debate on the effect of risk on auction behavior, our results give rise to a new puzzle. As risk is diminished and overbidding decreases for most of the value range, a significant degree of underbidding sets in for very low values
\end{abstract}

Keywords: risk, first-price auctions, risk-aversion, overbidding

JEL classification: C92, D44

${ }^{*}$ Financial support from the state Saxony-Anhalt is gratefully acknowledged. We thank audiences in Atlanta, Berlin, Maastricht, and Nottingham for helpful comments.

${ }^{\dagger}$ University of St Andrews, School of Economics and Finance, oliver@kirchkamp.de

${ }^{\ddagger}$ Maastricht University, Faculty of Economics and Business Administration, p.reiss@algec.unimaas.nl

${ }^{\S}$ University of Magdeburg, Faculty of Economics and Management, sadrieh@ww.uni-magdeburg.de 


\section{Introduction}

For first-price private value auctions, a plethora of experiments firmly established that there is overbidding relative to the risk-neutral Bayesian-Nash equilibrium prediction (Kagel, 1995). The leading explanation for this stylized fact received in the literature has been risk-aversion. However, recent research demonstrates that risk-aversion is not a fully satisfactory explanation. E.g., Cox, Smith, and Walker (1985) observe overbidding relative to the risk-neutral prediction in an auction experiment employing a lottery payoff procedure designed to induce risk-averse participants to submit risk-neutral bids. Kagel and Levin (1993) find overbidding relative to the risk-neutral prediction in third-price auction experiments where risk-averse bidders are predicted to bid less than risk-neutral bidders. Kirchkamp and Reiss (2004) demonstrate that there is substantial underbidding for small valuations if not precluded by the experimental design.

In this paper, we isolate the effects of risk experienced by bidders in first-price auction experiments in the presence of strategic uncertainty. We modify risk in a natural way by varying the number of income-relevant auctions that a participant plays with her bidding strategy in each round.

We find that the reduction of non-strategic risk moves observed bids closer to the risk-neutral Bayesian-Nash equilibrium prediction. Overbidding is reduced substantially for high valuations. However, we also find that underbidding for low valuation is more pronounced and occurs more often as the non-strategic risk is reduced.

\section{First-price auctions with reduced risk}

Consider a first-price auction setting with private values that are identically and independently distributed. In Bayesian-Nash equilibrium with a symmetric equilibrium bidding function, bidders face uncertain income prospects due to uncertainty about competitors' private values. These uncertain income prospects can be eliminated by averaging over an infinite number of auctions, where competitors' private values are randomly determined over and over again. In such a setting bidders' equilibrium payoffs are essentially deterministic and are equal to their expected equilibrium payoffs in the game played only once. When bidders use their bidding strategies in a finite number of auctions, intermediate risk situations arise that lie between full risk in a single auction and completely eliminated risk in infinitely many auctions. Thus, the uncertain income prospect can be gradually varied by varying the number of auctions in which each bidding strategy is used.

To formalize the idea of gradually varying risk, suppose that it is common knowledge that valuations $x$ are uniformly and independently distributed over $[0,1]$. Assume that utility func- 
tions have the form of $u(x)=x^{r}$ where $r$ is the parameter measuring attitude towards risk. ${ }^{1} \mathrm{~A}$ risk-neutral individual is described by $r=1$, a risk-averse individual is characterized by $r<1$. To identify a Bayesian-Nash equilibrium we follow the standard approach and assume that there is a symmetric and strictly increasing bidding function $\beta(x)$. In equilibrium, all bidders follow bidding function $\beta(x)$. For the case of two bidders, we have to show that if bidder 2 follows $\beta(x)$, then it is a best reply for bidder 1 to follow $\beta(x)$, too. Since $\beta(x)$ is strictly increasing, we can identify for each bid $b$ a valuation $z$ such that $b=\beta(z)$. Bidder 1 wins the auction if the other bidder's valuation is smaller than $z$. The probability of this event is $F(z)=z$. If the bidder plays $n$ auctions with the same bidding function, the bidder wins $k$ of these auctions with probability $\left(\begin{array}{l}n \\ k\end{array}\right) \cdot F(z)^{k} \cdot[1-F(z)]^{n-k}$. Bidder 1 maximizes

$$
\mathrm{EU}=\sum_{k=0}^{n}\left(\begin{array}{l}
n \\
k
\end{array}\right) \cdot F(z)^{k} \cdot[1-F(z)]^{n-k} \cdot u[k \cdot(x-\beta(z)]
$$

For a symmetric equilibrium it is necessary that we have $\partial \mathrm{EU} / \partial z=0$ and $z=x$. Given constant

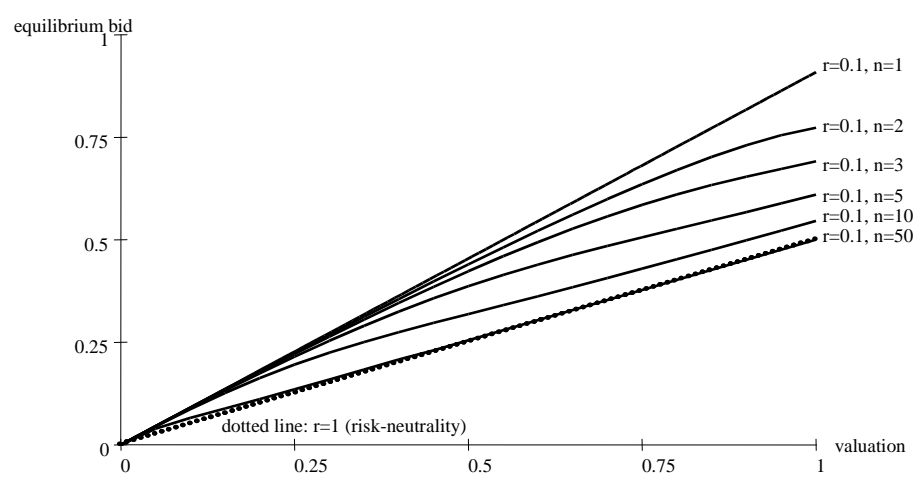

Figure 1: Equilibrium bidding functions for a risk-averse bidder and different numbers of incomerelevant auctions

relative risk-aversion $\left(u(x)=x^{r}\right)$ it is straightforward to solve the corresponding differential equation for the case $n=1$. With $\beta(0)=0$ we obtain the well-known equilibrium bidding function $\beta^{*}(x)=x /(1+r)$. For $n=2$ it is possible to find a closed-form solution. For $n>2$ we have to resort to numerical approximations. Figure 1 depicts equilibrium bidding functions for the case of a very risk-averse bidder with very low risk-tolerance $r=0.1$ together with the equilibrium bidding function for a risk-neutral bidder. The Figure illustrates that even in the case of strong risk-aversion, the equilibrium bidding function approaches the equilibrium bidding function of a risk-neutral bidder provided the number of played auctions is sufficiently high.

\footnotetext{
${ }^{1}$ Smith and Walker (1993) report that upward scaling the conversion rate at which laboratory currency is converted into cash has an insignificant effect on mean bid deviations from risk-neutral equilibrium bids. The utilized utility function is the only functional form satisfying scale independence of payoffs.
} 


\section{Experimental design}

We implemented the auction of a single object with two bidders in the first-price sealed-bid design without reserve price. Experiments were conducted in June 2005 at the Magdeburg Experimental Laboratory (MaXLab) at the University of Magdeburg. A total of 214 subjects participated in these experiments. All experiments were computerized with the software z-Tree (Fischbacher, 1999).

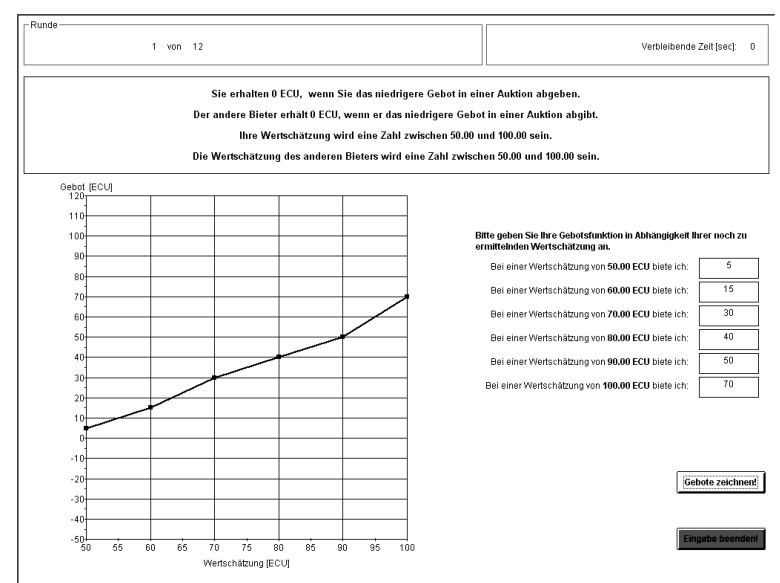

Figure 2: A typical input screen in the experiment (hypothetical data)

In the experiments we employed the strategy method to elicit bidding functions. We required participants to specify their bids for six different valuations $(50,60, \ldots, 100)$. Bids for valuations that are between those six valuations are obtained by linear interpolation. Figure 2 displays a typical input screen that participants faced to submit their bidding strategy in each round. This method to submit bidding strategies remained unchanged across all rounds and treatments.

Table 1: Treatment variables, treatment short-hands and number of independent observations

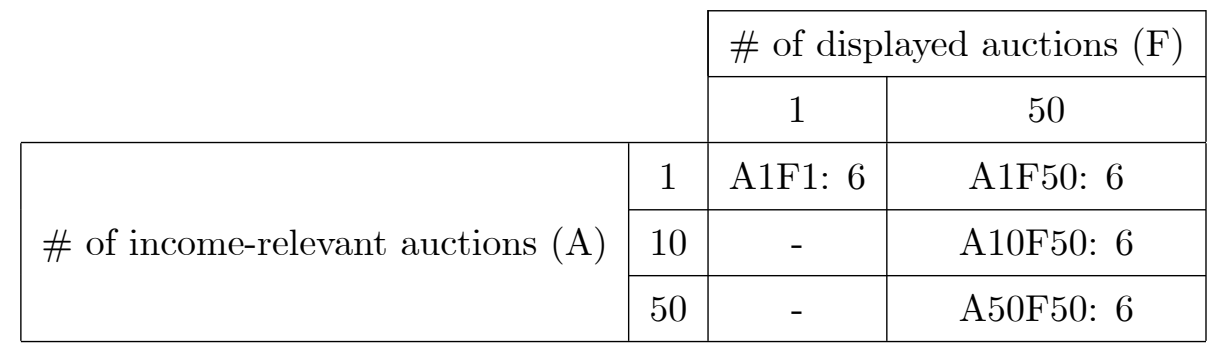

There were twelve rounds in each treatment. In each round each participant was randomly matched with one other participant.

In order to explore the role of risk in first-price auctions, we consider two treatment variables: the number of income-relevant auctions (A) and the number of auctions whose outcome is 
displayed to participants as feedback $(\mathrm{F})$. In each round a participant bids with her submitted

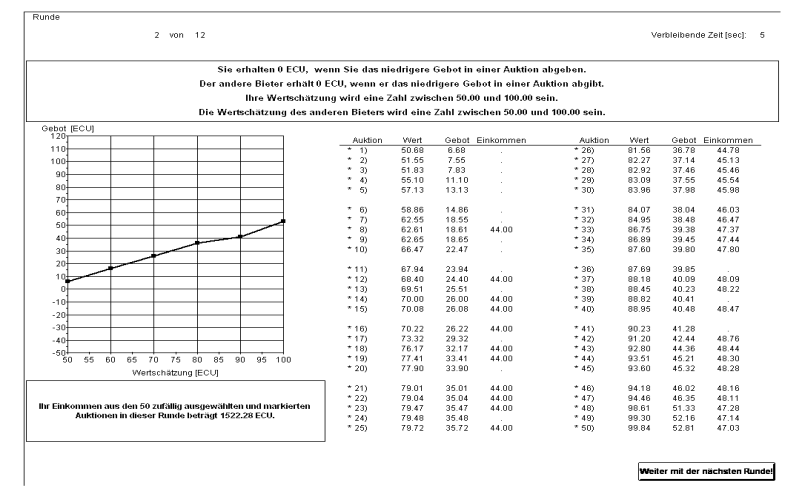

Figure 3: A typical feedback screen in the experiment (treatment A50F50, hypothetical data)

bidding strategy against her matched competitor in a fixed number of auctions which was either exogenously set to one or fifty. For every single auction of each round, the valuation assigned to each participant is independently drawn from a uniform distribution with domain $[50,100]$. To determine the income of a participant in a given round, a subset of all displayed auctions is selected at random and the corresponding auction income is added up. The number of selected auctions that was relevant for income determination was either one, ten, or fifty. If an auction outcome was income-relevant, it was marked in the feedback screen with an asterisk.

Figure 3 illustrates a typical feedback screen for the treatment A50F50 where participants played 50 different auctions per round which all were used to compute the round income. Analogously in the treatments with ten income-relevant auctions where 50 auctions were played, ten auctions were marked. In the treatment with one income-relevant auction, 50 auctions were played and 1 of them was marked.

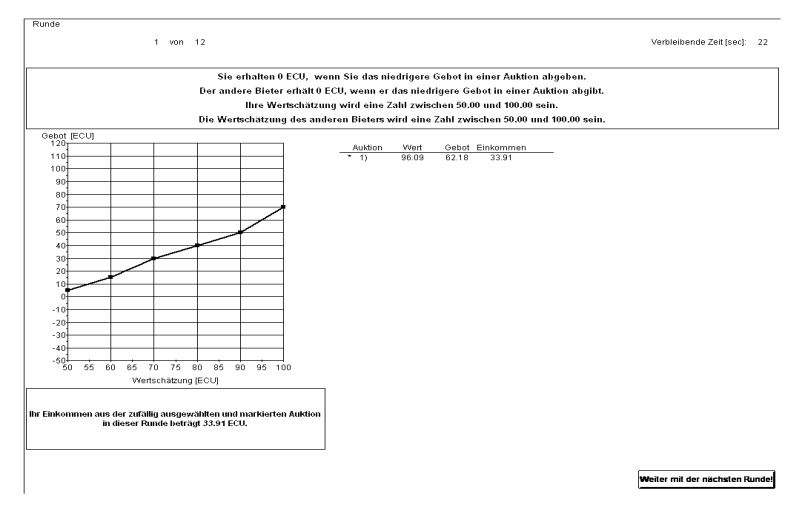

Figure 4: A typical feedback screen in the experiment (treatment A1F1, hypothetical data)

Figure 4 shows a typical feedback screen for the treatment A1F1 where there was only a 
single played auction per round that was used to compute round income. Table 1 summarizes the treatments that we investigated. It provides the shorthand-notation for each treatment and the number of independent observations that we obtained.

\section{Experimental results}

\subsection{Feedback effect}

In this subsection we investigate the effect of increasing feedback on bidding behavior. Feedback on outcomes is provided for 50 played auctions while a single one among them is selected at random to completely determine round income. A priori one might expect that if increasing feedback has any influence on bidding behavior, then it would lead participants to bid closer to the risk-neutral equilibrium; for evidence that auction feedback can impove the explanatory power of theory to some limited extent see, e.g., Brosig and Reiss (2007).

For a first impression whether multiple feedback has an effect, Figure 5 depicts average bidding functions for treatments $\mathrm{A} 1 \mathrm{~F} 1$ and $\mathrm{A} 1 \mathrm{~F} 50 .{ }^{2}$ Average bids are provided in Table 2. If feedback is introduced deviations from risk-neutral equilibrium are slightly reduced. Average

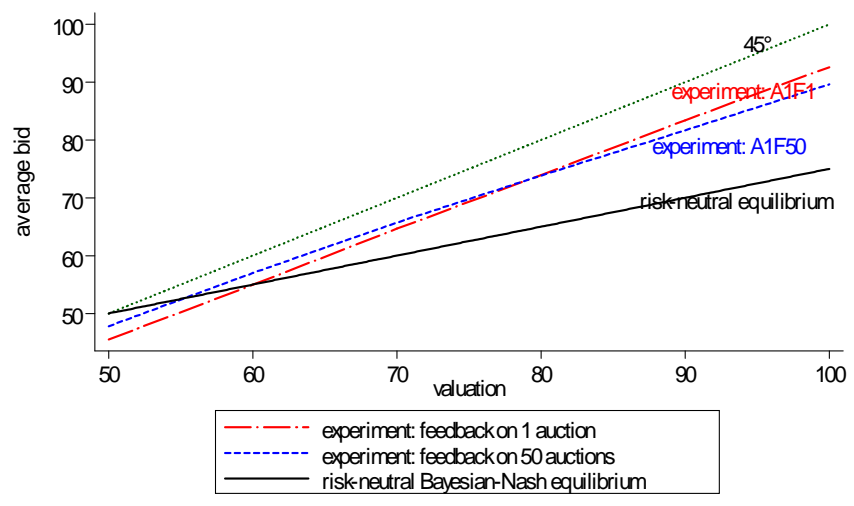

Figure 5: Feedback effect in the experiment if the number of auctions displayed increases

bids appear to be not strongly influenced by feedback as Table 2 and Figure 5 suggest. To see if there are statistical differences between average bids for any given valuation, we employ Mann-Whitney- $U$-tests where the results are provided in the last row of Table 2. We apply this and all other tests (including the t-test) on averages on independent observation level. As can

\footnotetext{
${ }^{2}$ All figures, tables, and statistics provided in this section base on data that we obtained for rounds 7-12 since bidding behavior appears to have stabilized for the second half of the experiment in terms of the number of bid changes over time and the size of bid changes, cf. Kirchkamp and Reiss, 2004. However, if we make use of our full data set and include data that we obtained for rounds 1-6 in our analyses, none of the conclusions are affected.
} 
Table 2: Average bids and average MSD by treatment

\begin{tabular}{cccccccc}
\hline valuations & 50 & 60 & 70 & 80 & 90 & 100 & MSD \\
\hline RNNE-bid & 50 & 55 & 60 & 65 & 70 & 75 & \\
A1F1 & 45.5 & 54.9 & 64.7 & 73.9 & 83.4 & 92.6 & 125.3 \\
A1F50 & 47.8 & 57.0 & 65.8 & 73.9 & 81.7 & 89.6 & 104.4 \\
\hline p-values & .025 & .0782 & .2623 & .5218 & .3367 & .0547 & .337 \\
\hline \multicolumn{7}{c}{ The $p$-values are for two-tailed Mann-Whitney U tests. }
\end{tabular}

be seen from the table, average bids differ significantly only for the extreme valuations, i.e. 50, 60, and 100 ECU.

To see if feedback significantly reduces deviations from risk-neutral equilibrium, we measure the global distance between observed bids and the risk-neutral equilibrium bidding function by computing the mean of squared deviations from risk-neutral bids (MSD) for each observed bidding function

$$
\frac{1}{6} \sum_{v \in\{50,60,70,80,90,100\}}\left(b_{v}-\beta_{v}^{\mathrm{RN}}\right)^{2} .
$$

Neither the $t$-test (two-tailed, $p=0.198$ ) nor the Mann-Whitney- $U$-test (two-tailed, $p=0.337$ ) identifies a significant feedback effect on mean squared deviations from equilibrium. This suggests that multiple auction outcome feedback is, here, a secondary determinant of bidding behavior. It follows that our results on risk variation given below do not stem from the introduction of extensive feedback on auction outcomes.

\subsection{Risk effect}

In the experiment we decrease the risk of bidders by increasing the number of auctions that a bidder played with a submitted bidding function and whose outcomes are used to determine a participant's income. In our treatments A1F50, A10F50, and A50F50, each participant played 50 auctions with the same submitted bidding function per round. In treatment A1F50 (A10F50), a single auction (ten auctions) out of these 50 auctions was (were) selected at random. The outcome of these auctions fully determined the participant's round income. In treatment A50F50, all 50 auctions were selected and used to determine the participant's round income. Evidently risk is much smaller in the treatment where 50 different auctions determine the round income.

The left panel in Figure 6 depicts the average bidding function observed in treatments A1F50 and A50F50. ${ }^{3}$ Average bids for each treatment are listed in Table 3. The graph shows that increasing the number of income-relevant auctions from 1 to 50 shifts the average bidding function

\footnotetext{
${ }^{3}$ The average bidding function for treatment A10F50 is not depicted to keep the figure clear-cut, but average bids for this treatment are tabulated.
} 

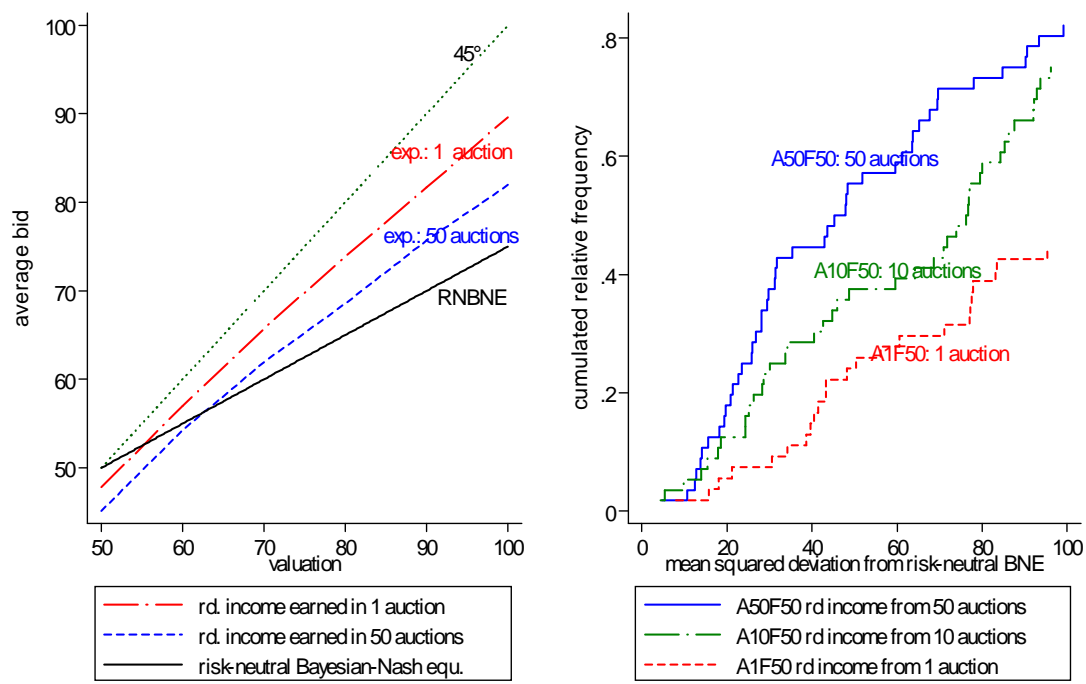

Figure 6: Bidding strategy effect in the experiment if the number of auctions played with a single bidding strategy increases.

Left panel: Average bidding functions. Right panel: Cumulative frequencies for squared deviations from riskneutral equilibrium bidding.

strongly downward. Hence, bidding is less aggressive if risk is eliminated. Indeed, risk-averse equilibrium bidding predicts smaller bids if risk is reduced. Comparing average bids separately for each valuation observed in the A1F50 treatment to those in the A50F50 treatment using non-parametric Mann-Whitney- $U$-tests leads to significant differences for each comparison (twotailed MWU-test, $p<0.0375)$.

To test the hypothesis that average bids for each valuation decrease as the number of income-relevant auctions increases from 1 to 10 and further to 50, we employ the nonparametric Jonckheere-Terpstra test with the null that the median of average bids in each of the three treatments is the same and the alternative that medians are ordered. In addition to average bids, the last row of Table 3 provides the corresponding test statistics. As can be seen from the table, there is significant evidence that average bids decrease as the number of income-relevant auctions rises. ${ }^{4}$

A useful statistic to measure the distance between observed bidding functions and the riskneutral equilibrium prediction is the square of bidding deviations from risk-neutral equilibrium. The right panel in Figure 6 depicts cumulative distributions of squared equilibrium deviations averaged over participants and rounds in treatments A1F50, A10F50, and A50F50. It can be

\footnotetext{
${ }^{4}$ The test statistics for valuations 60 and 70 just miss the $5 \%$ level of significance which precisely obtains for $J=75$.
} 
Table 3: Average bids by treatment

\begin{tabular}{cccccccc}
\hline valuation & 50 & 60 & 70 & 80 & 90 & 100 & MSD \\
\hline A1F50 & 47.8 & 57.0 & 65.7 & 73.9 & 81.7 & 89.6 & 104.4 \\
A10F50 & 43.9 & 52.6 & 60.4 & 68.5 & 75.3 & 82.2 & 111.9 \\
A50F50 & 45.1 & 54.2 & 62.0 & 68.6 & 75.7 & 82.0 & 56.9 \\
\hline J.-T & $J=82$ & $J=74$ & $J=74$ & $J=91$ & $J=82$ & $J=89$ & $J=88$ \\
$p$-values & $p<.025$ & $p>.05$ & $p>.05$ & $p<.005$ & $p<.025$ & $p<.005$ & $p<.003$ \\
\hline \multicolumn{7}{l}{ The table provides test statistics J for the Jonckheere-Terpstra test and information on one-tailed $p$-values. }
\end{tabular}

seen that increasing the number of income-relevant auctions shifts the cumulated frequencies to the left. A Jonckheere-Terpstra test confirms that a larger number of auctions decreases mean squared deviations from equilibrium (one-tailed, $J=88, p<0.005$ ). In other words, reducing risk brings observed bidding functions closer to the risk neutral equilibrium. Specifically, the extreme reduction of risk explains $45.5 \%$ of all squared deviations from the risk-neutral equilibrium prediction that we observed in the bidding treatment A1F50 where standard risk prevailed.

\subsection{Risk, overbidding and underbidding}

In section 2 we have seen that an increase in the number of auctions reduces risk, and thus, the difference between the Bayesian-Nash equilibrium and the risk-neutral Bayesian-Nash equilibrium. The experimental results from section 4.2 support this finding. The larger the number of auctions, the smaller the deviation from the risk-neutral Bayesian-Nash equilibrium. A more careful inspection of Figure 6 reveals that this finding holds in particular for high valuations. For small valuations, however, playing more auctions actually increases the amount of underbidding, and this increases the distance to risk-neutral bids.

Figure 7 shows cumulative frequencies of bids for valuations of 50 and 100 . A $t$-test shows that underbidding significantly increases for a valuation of 50 (A1F50 vs. A50F50, one-tailed $t$-test, $p=0.0037$ ). Similarly overbidding significantly decreases for a valuation of 100 (A1F50 vs. A50F50, one-tailed $t$-test, $p=0.0005)$. This finding is consistent with Kirchkamp and Reiss (2004). They show that the presence of some boundedly rational bidders may yield underbidding of all bidders, even the rational ones, for small valuations. In such a setting risk-averse bidders still overbid for large valuations, though, overbidding decreases when risk is reduced. This is, precisely, what we observe in Figures 6 and 7. 

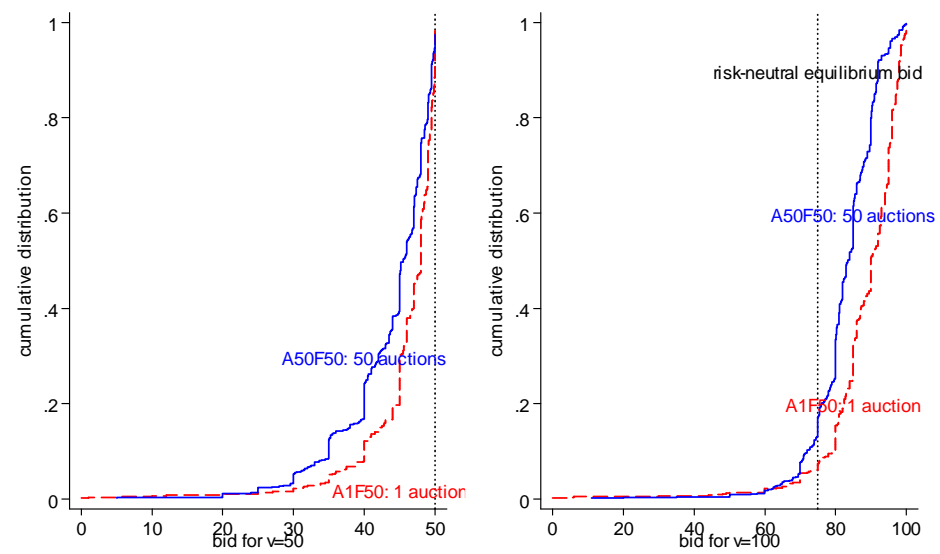

Figure 7: Cumulative frequencies of bids for valuation 50 (left) and valuation 100 (right) by treatment. The dotted line represents the risk-neutral equilibrium bid.

\section{Conclusion}

In this paper we set out to better understand the relation between risk and bidding behavior in auctions. Is risk-aversion a factor that leads to bids in first-price auctions higher than riskneutral equilibrium? To attack this question we introduce a novel design which allows us to control and gradually change the amount of risk bidders experience in auctions.

The results that we present in section 4.1 confirm the internal validity of our design. In section 4.2 we have seen that by reducing risk we, indeed, reduce the distance between experimental bids and the risk-neutral equilibrium bidding function. This finding supports the hypothesis that overbidding in auctions is at least partially due to risk-aversion. Overall, risk-aversion can explain $45.5 \%$ of squared deviations from risk-neutral equilibrium. A more detailed analysis in section 4.3 reveals that bids in the experiment approach risk-neutral equilibrium bids only for high valuations, i.e. valuations where overbidding is typically observed. For small valuations, where we typically observe underbidding, we observe that eliminating risk actually increases the distance of empirical bids from equilibrium bids, i.e. increases the amount of underbidding.

\section{Appendix}

\subsection{Procedures}

Participants were recruited by email and could register for the experiment on the internet. At the beginning of the experiment participants drew balls from an urn to determine their allocation to seats. Being seated participants then obtained written instructions. The experiment was computerized and we used the software package z-Tree (Fischbacher (1999). After answering 
control questions on the screen participants entered the treatment described in the instructions. After completing the treatment they answered a short questionnaire on the screen and were paid in cash.

\subsection{Instructions}

We used identical instructions in treatments A1F50, A10F50, and A50F50. The instructions for A1F1 were modified slightly to account for the fact that there is feedback on a single auction as opposed to 50 auctions. The instructions are in German. In the following we provide a translation.

\subsubsection{General information}

You are participating in a scientifc experiment that is sponsored by the state Saxony-Anhalt. If you read the following instructions carefully then you can|depending on your decision gain a considerable amount of money. It is, hence, very important that you read the instructions carefully.

The instructions that you have received are only for your private information. During the experiment no communication is permitted. Whenever you have questions, please raise your hand. We will then answer your question at your seat. Not following this rule leads to exclusion from the the experiment and all payments.

During the experiment we are not talking about Euro, but about ECU (Experimental Currency Unit). Your entire income will first be determined in ECU. The total amount of ECU that you have obtained during the experiment will be converted into Euro at the end and paid to you in cash. The conversion rate will be shown on your screen at the beginning of the experiment.

\subsubsection{Information regarding the experiment}

Today you are participating in an experiment on auctions. The experiment is divided into separate rounds. We will conduct 12 rounds. In the following we explain what happens in each round.

In each round you bid for an object that is being auctioned. Together with you another participant is also bidding for the same object. Hence, in each round, there are two bidders. In each round you will be allocated randomly to another participant for the auction. Your co-bidder in the auction changes in every round. The bidder with the highest bid obtains the object. If bids are the same the object is allocated randomly.

For the auctioned object you have a valuation in ECU. This valuation lies between 50 and $100 \mathrm{ECU}$ and is determined randomly in each round. The range from 50 to 100 is shown to you at the beginning of the experiment on the screen and is the same in each round. From this 
range you obtain in each round new and random valuations for the object. The other bidder in the auction also has a valuation for the object. The valuation that the other bidder attributes to the object is determined by the same rules as your valuation and changes in each round, too. All possible valuations of the other bidder are also in the interval from 50 to 100 from which also your valuations are drawn. All valuations between 50 and 100 are equally likely. Your valuations and those of the other player are determined independently. You will be told your valuation in each round. You will not know the valuation of the other bidder.

Experimental procedure The experimental procedure is the same in each round and is described in the following. Each round in the experiment has two stages.

\section{1st Stage}

In the first stage of the experiment you see the following input screen:

- screenshot of input mode; omitted here -

At that stage you do not know your own valuation for the object in this round. On the right side of the screen you are asked to enter a bid for six hypothetical valuations that you might have for the object. These six hypothetical valuations are 50, 60, 70, 80, 90, and 100 ECU. Your input into this table will be shown in the graph on the left side of the screen when you click on "draw bids". In the graph the hypothetical valuation is shown on the horizontal axis, the bids are shown on the vertical axis. Your input in the table is shown as six points in the diagram. Neighbouring points are connected with a line automatically. These lines determine your bid for all valuations between the six points for which you have made an input. For the other bidder the screen in the first stage looks the same. There are bids for six hypothetical valuations, too. The other bidder can not see your input.

\section{2nd Stage}

The actual auction takes place in the second stage of each round. In each round we will play [not in A1F1: not only] a single auction [not in A1F1: but fifty auctions]. This is done as follows:

[not in A1F1: Fifty times] a random valuation is determined that you have for the object. Similarly for the other bidder [not in A1F1: fifty random valuations are] [in in A1F1: one valuation is] determined. [not in A1F1: The screen lists all auctions ordered by valuations.] You see the following screen:

- screenshot feedback ${ }^{5}$; omitted here -

For [only in A1F1: your valuation] [not in A1F1: each of the fifty valuations] the computer determines your bid according to the graph from stage 1. If [in A1F1: your] [not in A1F1: a]

\footnotetext{
${ }^{5}$ The given screenshot for treatment $\mathrm{A} 1 \mathrm{~F} 1$ differed from that for all other treatments only in the number of displayed auctions. Drawn valuations, bids, and incomes were always replaced by '...' in all instructions.
} 
valuation is precisely at $50,60,70,80,90$, or 100 the computer takes the bid that you gave for this valuation. If [in A1F1: your] [not in A1F1: a] valuation is between these points your bid is determined according to the joining line. In the same way the [in A1F1: bid] [not in A1F1: bids] of the other bidder [in A1F1: is ] [not in A1F1: are] determined [not in A1F1: for his fifty valuations]. Your bid is compared with the one of the other bidder. The bidder with the higher bid obtains the object. If you are the bidder with the higher bid, then your income from this auction will be shown. If you are the bidder with the smaller bid, then a dot (.) will be shown instead of the income.

\section{Your income from the auction:}

[not in A1F1: A fixed number of auctions out of all 50 auctions will be randomly selected and marked by an asterisk $\left(^{*}\right)$. The outcomes of these marked auctions determine your income in this round. All auctions that are not marked do not change your account balance. The number of marked auctions is the same in every round and will be shown on a screen at the start of the experiment.]

[not in A1F1: For each of the randomly selected auctions that are marked by an asterisk $\left(^{*}\right)$ the] [only in A1F1: The] following holds:

- The bidder with the higher bid obtains the valuation he had for the object in this auction added to his account minus his bid for the object.

- The bidder with the smaller bid obtains no income from this auction.

You total income in a round is [not in A1F1: the sum of] the ECU income from the [not in A1F1: marked auctions] [in A1F1: auction] in this round where you have made the higher bid.

This ends one round of the experiment and you see in the next round again the input screen from stage 1. At the end of the experiment your total ECU income from all rounds will be converted into Euro and paid to you in cash together with your Show-Up Fee of 3.00 Euro.

Please raise your hand if you have questions. 


\section{References}

[1] Brosig, Jeannette, and J. Philipp Reiss (2007): Entry Decisioncs and Bidding Behavior in Sequential Procurement Auctions: An Experimental Study, Games and Economic Behavior $58(1), 50-74$.

[2] Cox, James C., Vernon L. Smith, and James M. Walker (1985): Experimental Development of Sealed-Bid Auction Theory: Calibrating Controls for Risk Aversion, American Economic Review 75(2), 160-165.

[3] Fischbacher, Urs (1999): z-Tree. Toolbox for Readymade Economic Experiments, IEW discussion paper 21, University of Zurich.

[4] Holt, Charles A. and Susan K. Laury (2002): Risk Aversion and Incentive Effects, American Economic Review 92(3), 1644-1655.

[5] Kagel, John H. (1995): Auctions: a survey, in: Kagel, John H. und Alvin E. Roth (eds.), Handbook of Experimental Economics. Princeton: Princeton University Press, 501-585.

[6] Kagel, John H. and Dan Levin (1993): Independent private values auctions: Bidder behavior in first-, second-, and third-price auctions with varying numbers of bidders, Economic Journal 103, 868-879.

[7] Kirchkamp, Oliver and J. Philipp Reiss (2004): The overbidding-myth and the underbiddingbias in first-price auctions, SFB 504 discussion paper 04-32, University of Mannheim.

[8] Smith, Vernon L. and James M. Walker (1993): Rewards, Experience and Decision Costs in First Price Auctions, Economic Inquiry 31, 237-245. 